\title{
Research
}

\section{Power and Conflict in Adaptive Management: Analyzing the Discourse of Riparian Management on Public Lands}

\author{
Jennifer S. Arnold $^{1}$, Mirka Koro-Ljungberg ${ }^{2}$, and Wendy-Lin Bartels ${ }^{3}$
}

\begin{abstract}
Adaptive collaborative management emphasizes stakeholder engagement as a crucial component of resilient social-ecological systems. Collaboration among diverse stakeholders is expected to enhance learning, build social legitimacy for decision making, and establish relationships that support learning and adaptation in the long term. However, simply bringing together diverse stakeholders does not guarantee productive engagement. Using critical discourse analysis, we examined how diverse stakeholders negotiated knowledge and power in a workshop designed to inform adaptive management of riparian livestock grazing on a National Forest in the southwestern USA. Publicly recognized as a successful component of a larger collaborative effort, we found that the workshop effectively brought together diverse participants, yet still restricted dialogue in important ways. Notably, workshop facilitators took on the additional roles of riparian experts and instructors. As they guided workshop participants toward a consensus view of riparian conditions and management recommendations, they used their status as riparian experts to emphasize commonalities with stakeholders supportive of riparian grazing and accentuate differences with stakeholders skeptical of riparian grazing, including some Forest Service staff with power to influence management decisions. Ultimately, the management plan published one year later did not fully adopt the consensus view from the workshop, but rather included and acknowledged a broader diversity of stakeholder perspectives. Our findings suggest that leaders and facilitators of adaptive collaborative management can more effectively manage for productive stakeholder engagement and, thus, socialecological resilience if they are more tentative in their convictions, more critical of the role of expert knowledge, and more attentive to the knowledge, interests, and power of diverse stakeholders.
\end{abstract}

Key Words: collaboration; conflict; critical discourse analysis; dialogue; facilitation; livestock grazing; public participation; riparian management, social learning, stakeholder engagement

\section{INTRODUCTION}

Engaging diverse stakeholders in adaptive management, referred to as adaptive collaborative management, is increasingly considered important to maintaining resilience in coupled social-ecological systems (Liu et al. 2007). Collaboration in this context is expected to stimulate learning about complex systems, establish social legitimacy for decision making, and build relationships that reinforce commitments to learning and adaptation in the long term (Stringer et al. 2006, Pahl-Wostl et al. 2007, Jacobson et al. 2009).

However, implementation of adaptive collaborative management often falls short of this ideal. Stakeholders draw from different values and bodies of knowledge to define problems and propose solutions. Such diversity can stimulate learning and innovation, but it can also create conflict and intensify struggles over power, especially with regard to controversial issues (Lipscomb and O'Connor 2002, Healy 2009, Larson et al. 2009). For example, powerful stakeholders may dominate discussions and overshadow competing ideas, or less powerful stakeholders may lack the capacity to share their ideas effectively (Armitage et al. 2008, Reed 2008).

The professional practice of facilitation has emerged in response to this need to help groups productively manage their differences. Facilitators are expected to establish ground rules and guide group interaction to foster balanced participation, empathic listening, dialogue, and, as appropriate, collective decision making (Hogan 2002). When individuals open up to one another through respectful interpersonal communication, destructive conflicts can be transformed into productive opportunities for learning and integrative problem solving (Putnam and Wondolleck 2003, Kahane 2007). This collaborative approach to learning and decision making emphasizes that everyone has valuable knowledge to contribute. It is especially critical of expert knowledge, which may be used to eclipse the contributions of others (Healy 2009).

Despite the practical challenges of engaging diverse stakeholders, many complex resource problems require a collaborative, or at least a coordinated, approach to planning and management because of interdependencies between social and ecological systems (Ostrom 2008). For this reason, many researchers indicate the need for more critical research on how collaborative processes function, with special consideration to issues of power and marginality (Leeuwis 2000), so that we may establish more realistic expectations of adaptive collaborative management (Innes and Booher 1999, Armitage et al. 2008, Muro and Jeffrey 2008).

\footnotetext{
${ }^{1}$ School of Natural Resources and the Environment, University of Florida, ${ }^{2}$ School of Human Development and Organizational Studies, University of Florida, ${ }^{3}$ Florida Climate Institute, University of Florida
} 
This study is situated in the context of a multiyear collaborative effort supporting adaptive management of livestock grazing on a National Forest in the southwestern USA. A series of professionally-facilitated workshops brought together diverse stakeholders to discuss the controversial issue of livestock grazing in riparian areas. While we researched this collaborative process more broadly (Arnold 2011), this study focuses specifically on one field day from the series of workshops to address the following research questions: (1) How did participants interact in workshop discussions to expand their understanding of the social-ecological system, and (2) How did the ideas discussed during this field day compare to subsequent decisions in the published management plan for this area? Using critical discourse analysis, we examined transcripts of workshop discussions and text from the management plan to understand how participants of adaptive collaborative management negotiated learning and decision making.

Rather than characterizing the complex, multiyear collaborative process in its entirety, our analytical approach takes a constructionist epistemological orientation to understand how meanings are socially constructed in particular contexts (Kincheloe 2005). Specifically, this study presents and discusses key instances of stakeholder interactions that we identified as salient to negotiating management decisions in this particular social-ecological context. This type of discursive research acknowledges the socially-situated nature of language, behavior, and experiences, and the existence of multiple possible interpretations of data depending on one's social perspective. According to a constructionist epistemology, researchers are not expected to present findings that are "absolutely true" for extrapolation elsewhere, but rather to present a consistent and logical interpretation of data that represents one of many possible interpretations (Kincheloe 2005). The responsibility is placed on readers to decide how insights generated in one study may apply to other situations and the readers' own contexts and experiences. Fischer (2009) calls for more such constructivist ${ }^{\dagger}$ research to stimulate debate among managers and policy makers about how theories of environmental management and public participation can be applied to real world situations.

We will present our analysis of workshop discussions and the management plan by examining how workshop participants made claims about the social-ecological system and how they considered claims made by others. The passages presented here were selected to highlight instances in which differences in stakeholder perspectives most clearly surfaced on the topic of riparian management. In particular, we focus on the power of facilitators, who guided participant interactions in the workshop, and the power of US Forest Service (FS) staff, who wrote the management plan. We conclude with suggestions for how leaders, facilitators, and participants of adaptive collaborative management can critically reflect on their own practices to more effectively manage power dynamics and stakeholder diversity.

\section{CONFLICT AND COLLABORATION}

The conflict management literature recognizes the plurality of stakeholder interests and power issues underlying participatory and consensus-based approaches to decision making (Susskind et al. 1999, Kaner 2006). According to interest-based negotiation, powerful stakeholders may choose not to participate if they feel it is in their best interest to act individually or if the situation is framed in a way that does not correspond with their interests (Fisher et al. 1991, Lewicki et al. 2003). Conflict situations can become polarized and destructive, even intractable, when issues in conflict are closely related to stakeholders' sense of identity, as is often the case in conflicts over agriculture and conservation; however, conflict management specialists stress that even the most intractable conflicts can transition into productive relations (Putnam and Wondolleck 2003).

With situations characterized by conflict or misunderstanding, facilitators who have no direct interest in the situation can help establish the trust needed for stakeholders to work together productively by establishing a fair process that does not favor any stakeholder group, nor influence the content of a group's conclusions (Heron 2002). At the same time, recognizing that stakeholders have different capacities to participate, many collaborative processes explicitly include training and capacity-building activities to promote a fair process. In these situations, facilitators often act as instructors and experts, especially when the role of expert knowledge is not critically considered. However, when instructional concepts dismiss or reject the ideas of some participants, they can become frustrated by facilitators and lose trust in the process (Rixon et al. 2007).

Powerful stakeholders, especially leaders of collaborative processes, also tend to have substantial influence over a group's process and outcomes; they often establish the forum, define the purpose and scope of the process, hire the facilitator, set the agenda, and invite participants (Connelly and Richardson 2004). Unlike facilitators, these stakeholders generally do not have the training to recognize the subtle influences that their actions may have on group dynamics and outcomes. In practice, leaders of collaborative efforts, whether consciously or unconsciously, may be more interested in strategic action, in which the process is used to secure their own interests, than communicative action, in which the process is genuinely used to encourage learning and negotiate decisions collectively (Habermas 2000). A collaborative or participatory process can ironically become oppressive if powerful stakeholders influence the process to such a degree that participants must either agree with predetermined conclusions or abandon the process (Cooke and Kothari 2001, Bush and Folger 2005). 


\section{COMPETING DISCOURSES OF RIPARIAN MANAGEMENT}

As the conflict over riparian management has evolved, two competing discourses have framed the debate: the environmental discourse, which advocates removal of livestock to maximize riparian protection and restoration, and the agricultural science discourse, which advocates for adaptive livestock management and monitoring to implement grazing strategies that have negligible riparian impact. Concern about riparian degradation in the western USA was first raised by the environmental movement in the 1960s. Through media campaigns and legal action, environmentalists identified livestock as the principal cause of riparian degradation and concentrated their efforts on removing livestock from public lands. At that time, heavy livestock impacts to riparian areas, commonly called "sacrifice areas," were more or less accepted as part of the cost of doing business (Quigley 2005:40). Yet once environmentalists raised the issue, land managers acknowledged that riparian degradation was a problem and that the livestock practices in common use at that time were unacceptable (Elmore and Beschta 1987). Starting in the 1970s, agricultural leaders invested in research and education to identify and promote best management practices for "proper grazing" that would result in little to no impact on riparian function (e.g., Winward 2000, Wyman et al. 2008). Meanwhile, environmental scientists and activists have continued to advocate for excluding livestock from riparian areas (e.g., Fleischner 1994, Matteson and Wuerthner 2002).

\section{METHODS}

\section{Riparian workshops on the Sprucedale National Forest}

The Sprucedale ${ }^{\ddagger}$ National Forest $(800,000+$ ha) in the southwestern USA is known for its high density of riparian areas, including springs, wetland meadows, lakes, streams, and the headwaters of several regionally important rivers. Because of its large number of endangered species, mostly associated with riparian areas, Sprucedale National Forest has been the focus for environmental activism and litigation for several decades. Like all National Forests, Sprucedale is managed for multiple uses, including recreation, fishing, hunting, and livestock grazing although planning guidelines emphasize that multiple uses will be permitted only when resource conditions allow.

In the mid-1990s, the Forest Service conducted Environmental Assessments of grazing activities on Sprucedale and decided to fence out livestock from many streams and wetlands, especially those designated as critical habitat for endangered species. In other riparian areas, they enforced stricter guidelines and shorter time periods for livestock grazing. These actions precipitated great tensions between ranchers with grazing permits on Sprucedale and FS staff, especially
Resource Specialists, whom ranchers associated with these changes.

Frustrated by years of unproductive conflict, a group of stakeholders associated with Sprucedale organized a series of workshops to open discussion on the controversial topic of riparian grazing. Workshop organizers included a university extension specialist, proactive Sprucedale ranchers, Sprucedale FS staff, and the lead author, who was then a doctoral student. Organizers invited a governmental facilitation team, who specialized in managing conflicts associated with riparian grazing on public lands, to lead the series of workshops. The informal slogan of the workshops used in publicity materials was "transforming conflict into collaboration for improved stewardship of riparian resources." Organizers hoped the workshops would attract a diversity of stakeholders, especially Resource Specialists and skeptical Sprucedale ranchers, so that conflicts over riparian grazing could be worked out through scientific presentations and group discussions in the field. Funding for the workshops came from university extension, the state cattle growers' association, the FS regional office, and a regional nonprofit organization dedicated to sustainable ranching.

Reflecting their program's objective to integrate the social and ecological dimensions of public land management, the facilitation team sought to build participants' capacity for adaptive collaborative management by teaching communication skills, conflict management, riparian assessment, and grazing management. Workshop activities directed participants to apply concepts to real-world management questions. Thus, each member of the facilitation team took on the dual roles of facilitating collaborative problem solving and teaching skills and concepts. The team included professional facilitators, who had extensive conflict management experience, and riparian instructors, who included some of the early innovators and contemporary leaders of sustainable livestock management in riparian areas. For example, one of the facilitators, Steve, worked with researchers who gathered extensive data on riparian conditions and livestock grazing practices throughout the western USA in the 1970s; he testified on this issue in Congress; and he helped develop the riparian assessment protocol taught in the workshops and currently used by the Forest Service. Facilitators led the series of workshops using standard workshop formats they had previously developed, including a two-day workshop on consensus building, a fourday workshop on riparian assessment, and a three-day workshop on riparian monitoring (Table 1). Facilitators structured workshop activities to engage all participants in activities and discussion.

From the workshops, we identified seven participating stakeholder groups who had shared interests in riparian management: (1) workshop facilitators, (2) university affiliates, (3) Sprucedale FS staff, (4) Sprucedale ranchers, (5) 
Table 1. Dates, locations, and number of participants for the series of riparian workshops held on the Sprucedale NF in 2009. Transcripts from the June 23 workshop were used for in-depth analysis in this study.

\begin{tabular}{lllc}
\hline \hline Date & Workshop Topic & Location & $\begin{array}{c}\text { Number of } \\
\text { Participants }\end{array}$ \\
\hline Feb 3 & $\begin{array}{l}\text { Consensus Building - } \\
\text { Build trust and identify } \\
\text { problems }\end{array}$ & Indoor & 60 \\
Feb 4 & $\begin{array}{l}\text { Consensus Building - } \\
\text { Discuss problems and } \\
\text { collaborative solutions }\end{array}$ & Indoor & 51 \\
June 22 & $\begin{array}{l}\text { Riparian assessment - } \\
\text { Presentations }\end{array}$ & Indoor & 59 \\
June 23 & $\begin{array}{l}\text { Riparian assessment - } \\
\text { Field practice }\end{array}$ & High elevation sites & 40 \\
June 24 & $\begin{array}{l}\text { Riparian assessment - } \\
\text { Field practice }\end{array}$ & Mid elevation sites & 32 \\
June 25 & $\begin{array}{l}\text { Riparian assessment - } \\
\text { Field practice } \\
\text { Aug 25 }\end{array}$ & $\begin{array}{l}\text { Riparian monitoring - } \\
\text { Presentations }\end{array}$ & Low elevation sites \\
Aug 26 & $\begin{array}{l}\text { Riparian monitoring - } \\
\text { Field practice }\end{array}$ & High elevation site & 49 \\
Aug 27 & $\begin{array}{l}\text { Riparian monitoring - } \\
\text { Presentations } \\
\text { Mean participants per } \\
\text { workshop } \\
\text { Total participants }\end{array}$ & Indoor & 30 \\
\hline & & & 45 \\
\hline
\end{tabular}

ranchers from other areas, 6) staff from the state wildlife agency, and (7) environmentalists (Table 2). We further subdivided Sprucedale FS staff by job responsibilities to distinguish slightly different perspectives on riparian management. Sprucedale Leadership, such as District Rangers who have decision-making authority within their administrative districts, take ultimate responsibility for protecting forest resources, effectively managing public relations, and complying with laws and regulations to avoid litigation. Range Specialists, who work closely with ranchers to administer grazing permits and often come from agricultural backgrounds themselves, recommend grazing management practices based on their assessment of what the resources can sustain. Resource Specialists, such as wildlife biologists and hydrologists, tend to assess resource conditions more conservatively since they are more interested in resource protection and restoration than extractive land uses, such as livestock grazing. However, we emphasize that FS staff work in interdisciplinary teams with the shared mission of sustainable management, and all FS staff in this study expressed a personal commitment to protecting the biodiversity and ecological function of forest resources.

\section{Data collection and analysis}

The primary data used in this study are transcribed audio recordings from a riparian assessment workshop held in the field on June 23, 2009 (Table 1) and the FS management plan for the field sites visited, which was published one year later. The mix of stakeholders in attendance and their participation levels in this workshop mirrored the diversity of participation throughout the workshop series (Table 2). Based on analysis of all workshop transcripts, we identified recurring controversial themes where stakeholder differences most clearly surfaced, namely, interpreting current conditions, managing uncertainty, and determining causes of degradation. We selected the June 23 workshop for in-depth analysis because this was the only workshop day where the field sites were specifically chosen by FS Leadership to inform revision of an adaptive management plan and because stakeholders expressed a diversity of views on these controversial themes. The management plan provides a unique opportunity to compare workshop discussions to FS decisions.

The analytic framework for this study draws from Fairclough's critical discourse theory, which describes how language is used to manage differences in power and meaning (Fairclough 1989, Fairclough 2008), and Bakhtin's dialogic theory, which frames learning as an exploration of difference among individuals in dialogue (Bakhtin and Emerson 1984). Fairclough presents five ways that differences in perspective can be managed and analyzed in critical discourse studies: (1) an accentuation of difference, as in polarization or a struggle over meaning and power; (2) a bracketing of difference, as in a focus on commonalities and solidarity; (3) an openness to, and exploration of, difference, as in Bakhtin's concept of dialogue; (4) overcoming differences, as in resolution; and (5) consensus, described as an acceptance of differences in power, which suppresses differences in meaning (Fairclough 2008). At the level of interpersonal communication, productive conflict management requires that stakeholders engage in dialogue and consider diverse views before making decisions, usually based on resolution or consensus (Daniels and Walker 2001). Although consensus is often loosely equated to agreement by all parties, it more accurately reflects the perspective of stakeholders with the most power and a lack of active opposition by others (Connelly and Richardson 2004, Fairclough 2008).

Working with the data, we examined: (1) the claims stakeholders made about the social-ecological system, (2) the certainty with which stakeholders made their claims, representing relative openness to other perspectives, (3) the justifications they gave to legitimize their claims, and (4) the ways they referenced or responded to claims made by other stakeholders. By examining how claims were made and considered by others, we identified patterns in how stakeholders managed differences in perspective using Fairclough's (2008) framework. Specifically, we looked for evidence of dialogue where participants considered alternative perspectives, which we interpreted as learning that has the potential to transform long-standing conflicts over riparian 
Table 2. Stakeholder participation in the series of workshops (left three columns) compared to participation in the workshop analyzed in this study (right four columns). Stakeholder groups are arranged in order of mean days attended per person, which loosely represents each stakeholder group's commitment to the series of workshops. "Number of speakers" is the number of participants who spoke during recorded workshop discussions. A "speaking turn" was counted each time a new speaker started talking or when a speaker changed topics.

\begin{tabular}{|c|c|c|c|c|c|c|c|}
\hline Stakeholder group & $\begin{array}{c}\text { Number } \\
\text { participants in } \\
\text { workshop series }\end{array}$ & $\begin{array}{l}\text { Percent } \\
\text { female }\end{array}$ & $\begin{array}{l}\text { Mean days } \\
\text { attended per } \\
\text { person }\end{array}$ & $\begin{array}{c}\text { Number of } \\
\text { participants at June } \\
23 \text { workshop }\end{array}$ & $\begin{array}{l}\text { Percent } \\
\text { female }\end{array}$ & $\begin{array}{c}\text { Number of } \\
\text { speakers at } \\
\text { June } 23 \\
\text { workshop } \\
\end{array}$ & $\begin{array}{l}\text { Percentage of } \\
\text { speaking turns }\end{array}$ \\
\hline Facilitators & 9 & $22 \%$ & 5 & 6 & $17 \%$ & 6 & $52 \%$ \\
\hline University affiliates & 11 & $57 \%$ & 5 & 5 & $80 \%$ & 3 & $1 \%$ \\
\hline \multicolumn{8}{|l|}{ Sprucedale FS staff } \\
\hline Range Specialists & 9 & $33 \%$ & 5 & 7 & $29 \%$ & 3 & $12 \%$ \\
\hline Leadership & 5 & $60 \%$ & 4 & 2 & $50 \%$ & 2 & $8 \%$ \\
\hline Fire Specialists & 1 & $0 \%$ & 3 & 1 & $0 \%$ & 0 & $0 \%$ \\
\hline Resource & 11 & $45 \%$ & 2 & 2 & $100 \%$ & 2 & $9 \%$ \\
\hline Specialists & & & & & & & \\
\hline Recreation & 1 & $0 \%$ & 2 & 0 & $0 \%$ & 0 & 0 \\
\hline Specialists & & & & & & & \\
\hline Sprucedale ranchers & 33 & $43 \%$ & 4 & 11 & $27 \%$ & 6 & $12 \%$ \\
\hline Other ranchers & 5 & $40 \%$ & 3 & 2 & $0 \%$ & 2 & $2 \%$ \\
\hline Environmentalists & 3 & $100 \%$ & 3 & 1 & $100 \%$ & 1 & $1 \%$ \\
\hline Wildlife agency staff & 5 & $20 \%$ & 2 & 2 & $0 \%$ & 1 & $1 \%$ \\
\hline $\begin{array}{l}\text { Other federal agency } \\
\text { staff }\end{array}$ & 12 & $25 \%$ & 2 & 2 & $0 \%$ & 0 & 0 \\
\hline Other public & 10 & $70 \%$ & 1 & 0 & $0 \%$ & 0 & 0 \\
\hline All groups & $\begin{array}{c}117 \\
\text { (total) }\end{array}$ & $\begin{array}{l}37 \% \\
\text { (mean) }\end{array}$ & $\begin{array}{c}3 \\
\text { (mean) }\end{array}$ & $\begin{array}{c}40 \\
\text { (total) }\end{array}$ & $\begin{array}{l}35 \% \\
(\text { mean) }\end{array}$ & $\begin{array}{c}26 \\
\text { (total) }\end{array}$ & $\begin{array}{l}100 \% \\
\text { (total) }\end{array}$ \\
\hline
\end{tabular}

grazing. We used QSR International's NVivo 7 software to manage the data and code controversial themes, while detailed discourse analysis was conducted manually.

\section{FINDINGS, INTERPRETATION, AND ANALYSIS}

We first discuss how stakeholders from the workshop positioned themselves as experts of this social-ecological system. Next, we present claims about the field sites relative to two controversial themes: interpreting current conditions and managing uncertainty. We then present claims from the management plan and compare these to claims from the workshop.

\section{Establishing expert knowledge}

Facilitators were invited to lead the workshops because of their expertise in riparian assessment and their experience managing riparian grazing conflicts on public lands. Taking on the role of riparian instructors, facilitators explained how to use the riparian assessment protocol, instructed participants to conduct an assessment of site conditions in small groups, and led group discussions, in which participants reported their findings and facilitators answered content questions. In response, most workshop participants positioned themselves as learners and active participants.
The Forest Service recognized the expertise of two of their own staff, namely, the Sprucedale Riparian Coordinator and a Resource Specialist, who had extensive riparian training and had monitored these sites in the 1990s. Although the Sprucedale Riparian Coordinator could not participate in this workshop due to scheduling conflicts, FS staff made frequent reference to his interpretation of the sites and his expectations for how they should be managed. The District Ranger explained, "[The Riparian Coordinator] couldn't be here today, but he and I have had a lot of discussions about these systems, which are pretty consistent, you know, with our high elevation grasslands and wet meadows." Notably, the Riparian Coordinator reviewed all riparian management plans.

Sprucedale ranchers identified themselves as experts on historical land use and land cover change on the basis that many of them came from multigenerational ranching families who homesteaded this area in the early 1900s. They also had expert knowledge of livestock and wildlife behavior from their daily observations of animal habits. Facilitators and FS staff recognized the value of ranchers' knowledge and regularly elicited their perspectives on these issues.

An independent researcher indirectly asserted her expert knowledge of southwestern riparian systems when she 
clarified a facilitator's statement about how sediments moved through the system. Although another facilitator confirmed her remark, no one explicitly acknowledged her expertise. She only made one other comment during the day, which was not picked up for discussion.

Finally, facilitators also identified themselves as experts of collaboration, conflict management, and consensus building. One of the facilitators, Don, concluded a discussion of site conditions by summarizing the consensus building process and positively evaluating the group's efforts:

To be honest with you, I think you all did a good
job, given the confusing situation we had here. ....
The final answers were pretty consistent all the way
through, with just a few variations here and there.
And that's what's nice about this, is you all kind of
arrived at the same spot. It might have been a little
bit, kind of like the creek out here, going [through]
a little bit different channels once in a while, but it
still came out the same way.

Yet, we found claims of expert knowledge did not necessarily grant stakeholders legitimacy within workshop discussions. As discussion leaders and riparian instructors, facilitators were positioned to acknowledge and elicit expertise from participants during the workshop. They enthusiastically highlighted the expertise of other facilitators, FS Leadership, Range Specialists, and ranchers, while they inconsistently recognized the expertise of Resource Specialists. In several cases, facilitators explicitly corrected statements about riparian function made by Resource Specialists, which implied they lacked expertise.

Facilitators also recognized the authority of FS Leadership to make management decisions, especially the District Ranger. They gave him frequent opportunities to redirect the discussion and elicit the expertise of others with the stated goal to link workshop discussions to management decisions. Although the District Ranger repeatedly recognized the Sprucedale Riparian Coordinator as an expert who played a key role in riparian management decisions, facilitators did not directly acknowledge the Riparian Coordinator's expertise nor explicitly respond to interpretations attributed to him. Neither the facilitators nor the District Ranger elicited the expertise of the independent researcher. Thus, in the workshops, we found the legitimacy of a person's perspective was largely established by those who had the power to lead discussions, elicit comments from others, and make concluding remarks. This was primarily the facilitators' role although, in some instances, the District Ranger redirected discussions to assert whose knowledge he considered legitimate with respect to management decisions.

\section{Interpreting current conditions}

At the first field site, participants observed a series of scoured out pools along the bottom of the drainage and new plant growth along the sides of the channel that stabilized the eroded banks. There was agreement that at an unknown time in the past, the site had been a wetland that held standing water for long periods of time, but that now it had transitioned, such that water flowed out of the system through the scoured out pools ${ }^{\S}$. Forest Service staff introduced the site by explaining that they were unsure how to interpret these erosion features. They acknowledged that the presence of new plant growth indicated that recent erosion had stabilized, but they were still somewhat concerned about the soil loss. A Range Specialist attempted to open dialogue on this point by tentatively describing her concerns: "We [saw] the quick revegetation, but still, the [area] that was being revegetated so quickly, was still below, a little bit, 6 inches to a foot, the original soil surface."

Facilitators attempted to resolve this concern by explaining that the series of scoured out pools was a natural erosion feature, which they called "necklace pools". They shared personal stories saying, "we've seen this situation in every state in the West." They explained that the necklace pools were a result of climatic changes since the last ice age and that with the current drying trend, the site received less precipitation, which reduced its ability to produce the vegetation needed to protect against erosion. Further, they explained that because this was a flat, low gradient system at the top of the watershed, there was not enough water flow to warrant concern.

Ranchers did not directly participate in this discussion and made only two indirect claims about current conditions when describing elk behavior. One rancher suggested erosion was a problem caused by elk, while another referred to the scoured areas as a natural feature that elk used for wallowing. The independent researcher did not make claims about current conditions.

The difference in interpretation between FS staff and facilitators was reflected in the specific words they used as the topic of erosion came up throughout the day (Figure 1). Facilitators most often used the words "headcut" or "downcut" to explain general concepts, but when referring to the field sites, they mostly used neutral terms, such as "necklace pools," "deposition pools", and "dissipation pools," to describe what they considered natural erosion features. In contrast, FS staff mostly used negative terms, such as "headcuts", "nickpoints", and "downcutting" to describe these same features. Both groups also used terms associated with the other's perspective, which could indicate some level of dialogue on the issue.

By qualitatively examining how FS staff and facilitators considered each other's claims about erosion, we found that FS staff, especially the Resource Specialists, attempted to engage in dialogue and explore differences with facilitators on multiple occasions throughout the day, while facilitators consistently used certainty and expert status to assert their own views, which closed off opportunities for dialogue. For example, one of the Resource Specialists, Helen, asked, "Just 
Fig. 1. Frequency of references to erosion categorized by usage and stakeholder group. Groups that did not mention erosion are not shown.

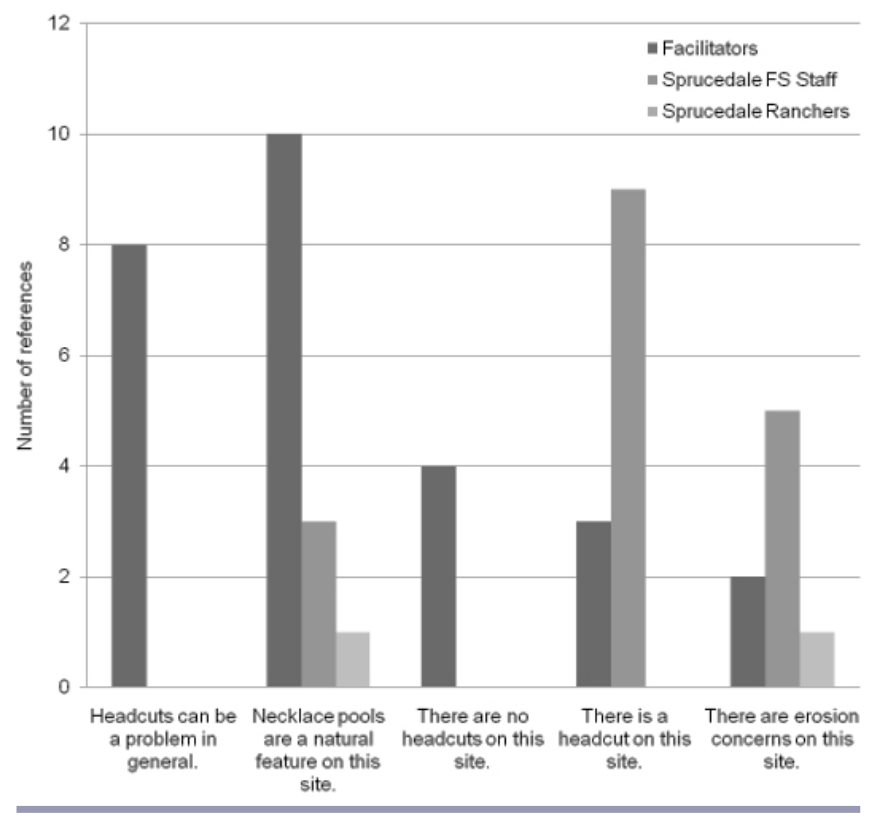

a quick question on those deposition pools. You know, it's not -It sounds like they're kind of functioning like a headcut in that they're just going to continue marching up, right? But they're repairing themselves as they go." In this quote, the Resource Specialist provisionally accepted the neutral term "deposition pool" that was used previously by facilitators, as she tentatively asserted her own claim of a "headcut" presenting a rational justification for her interpretation and inviting the facilitator to explore this difference in dialogue. When her initial comment was not picked up for discussion, she repeated her question a few minutes later:

\section{Resource Specialist, Helen: Do you think that's natural?}

\section{Facilitator, Don: Um hm.}

Resource Specialist: With the best management in the world you're going to see those little pockets?

Facilitator: Yeah, because I think we've got climatic things going on here. You know, the way this site was developed geologically, and then the climate we have today, as far as, you know, where we're at, you know, and stuff. It's part of Mother Nature.

In this example, the facilitator presented a rationalization in an attempt to resolve differences; however, his explanation relied on vague phrases such as "climatic things going on" and "part of Mother Nature." The strength of his claim lies in his dual status as discussion leader and riparian instructor, implying that he understands the natural potential of this site even if he does not explain it clearly here. However, claims based on expert authority close off opportunities to explore differences because one would have to challenge the source of the authority to open up discussion about the claim. Facilitators concluded this discussion by establishing consensus for their interpretation; however, FS staff continued to raise questions on this point throughout the day and in informal conversations following the workshop.

\section{Managing uncertainty}

Participants discussed how riparian systems are dynamic and difficult to predict due to disturbance from floods, droughts, and other watershed processes; they rarely demonstrate a gradual, linear progression toward recovery, which makes it difficult to determine how additional disturbances, such as livestock grazing, will affect recovery rates. During workshop discussions, FS staff repeatedly referenced uncertainty about how these sites would respond to management actions. All FS staff justified the need to reduce risk and uncertainty referencing their professional responsibility to protect Sprucedale's resources. The District Ranger, Robert, said: "Nobody's real certain that any of [these management options] will be successful, so that's why we're thinking-I don't know what we're thinking, except for, let's put up some exclosures, and try and get some idea of the potential of this site." His statement references a classic agricultural science approach to reducing uncertainty, where monitoring data is compared inside and outside of a livestock exclosure to interpret a site's response to grazing. Resource Specialists claimed that risk should be minimized when uncertainty is high. For example, the Resource Specialist who had extensive riparian monitoring experience explained that "maximum return of vegetative matter and vigor" could increase the chances of riparian recovery and that this could be achieved by excluding livestock and elk, among other management options. These suggestions were tentatively presented, indicating openness to different perspectives. All FS staff expressed concern that if erosion at this site continued, the system might cross some threshold, beyond which positive feedbacks would accelerate erosion and permanently drain the riparian areas.

Facilitators also acknowledged that riparian systems are complex, dynamic, and difficult to predict. However, they explained that monitoring data from different types of systems across the western USA have shown that riparian areas recover approximately as quickly with properly managed livestock grazing as without grazing. They explained that there is "too much noise in the system" due to climate and other factors to distinguish "natural rates of recovery," a term used by environmentalists opposed to riparian grazing, from "near natural rates of recovery," which they defined as an upward trend in conditions based on a minimum number of monitoring indicators. One of the facilitators, Steve, explained how he 
provided expert testimony in a court case questioning livestock impacts on endangered fish habitat. He justified his perspective to managing uncertainty by explaining, "that's been tested in court." Justification based on legal authority discourages participants from engaging in dialogue since an exploration of difference would require that the court decision be questioned. This encourages participants to accept and disseminate a whole discourse, or legal argument, rather than critically considering aspects of the discourse in dialogue with others.

When we examined how facilitators interacted with others on the topic of managing uncertainty, we found that they accentuated differences with FS staff, especially Resource Specialists, while they emphasized commonalities with ranchers. We see this pattern in the following exchange between a facilitator and the rancher who was permitted to graze this site:

\section{Facilitator, Ken: One of the things that frequently comes up is that people say, "Well, we really don't have anything against cows, but we want to see the streams recover faster." And so that's why this is such a significant thing that Steve [the other facilitator] is talking about, because, fact is, there is no natural rate of recovery that you can predict. It depends. As Steve said, there's too much noise in the system. You don't know if you're going to get enough rain or if it's going to be too hot. Or.}

Rancher, Evan: Too much rain.

Facilitator: Or if you're going to get some scouring event. You don't know, and so as long as you've got those upward trends and you can demonstrate it through those nine questions [from the assessment protocol], that's as good as you can get.

Rancher: So like what's demonstrated here today [with my livestock management] is as good as it's gonna get, but we're still in an upward trend, moving, healing those areas, right?

Facilitator: Yeah.

In the beginning of this example, the facilitator quoted an environmentalist claim, which was similar to previous claims made by Resource Specialists, that streams will recover faster without livestock grazing. He then strongly asserted that this approach is misguided, using the terms "fact is" and "there is no natural rate of recovery you can predict," which accentuated differences with the Resource Specialists and discouraged dialogue on this point.

Meanwhile, the facilitator and rancher worked together in this exchange to emphasize commonalities. The rancher finished the facilitator's sentence with the phrase, "too much rain,", and the facilitator elaborated this idea that too much rain could cause "a scouring event." Then the rancher repeated the facilitator's phrase "as good as you can get" and extended the facilitator's explanation of managing uncertainty to conclusions that this site was progressing toward recovery. The facilitator responded with encouragement, which further built solidarity between them. Then other facilitators went on to explain how monitoring data can be used to measure "near natural rates of recovery." Although they spent some time in dialogue exploring the possibility suggested by the District Ranger to put in livestock exclosures, they resolved this point by explaining that data associated with livestock exclosures can be difficult to interpret and that research had shown that monitoring data were sufficient to manage uncertainty.

\section{Comparing workshop discussions to the management plan}

While facilitators held the power to lead discussion and establish consensus in the workshop, FS staff held the power to make decisions on the National Forest. In the portion of the management plan specific to the riparian sites visited in the workshop, FS staff members describe conditions as unsatisfactory and requiring a change in management. Reflecting the Resource Specialists' perspective, the plan describes elk and livestock as the primary cause of soil compaction and the main driver of riparian degradation, such that faster recovery rates are expected with livestock exclusion. Yet, reflecting the facilitators' view of managing uncertainty from workshop discussions, the plan states: "An adaptive management approach to grazing allows for adjustments to livestock management so grazing impacts to the plwithant community's productivity and diversity are not greater than natural variability." The juxtaposition of these contrasting perspectives, in which differences are left acknowledged and unresolved, provides evidence that the interdisciplinary team of FS staff who wrote the plan considered and explored a diversity of stakeholder views.

The final FS decision allows conservative grazing as part of an adaptive management framework with the expectation that resource objectives can be met with "timely monitoring and corrective action." The plan presents a menu of management actions, including herding, fencing, and developing upland water, which can be used to correct negative livestock impacts identified from monitoring data associated with livestock exclosures. This decision represents resolution, where core differences about current conditions and uncertainty are integrated, yet still left somewhat intact. For example, the following passage acknowledges that riparian recovery may be slower with livestock grazing, but that progress can be expected with conservative monitoring guidelines:

Channels in this area leave something to be desired in terms of raw channel banks, occasional small head-cuts, and areas where bluegrasses are taking over native sedge vegetation. If stubble heights are 
maintained, especially going into fall/winter, this is expected to improve. Herding or other means of redistribution is expected to help this situation. Stubble height requirements are expected to allow raw banks to heal.

The description of current conditions, including "raw channel banks" and "occasional small headcuts," reflects the concerns of FS staff as expressed in the workshop, yet the language stops short of describing the site as degraded, which overall reflects the facilitators' consensus view that current conditions should not be considered a problem. Further, uncertainty is acknowledged with repeated use of the word "expected," as in "expected to improve." This language, rather than something stronger such as "will improve," signals uncertainty about whether site conditions can improve with livestock grazing, which is similar to the concern voiced by Resource Specialists and other FS staff in the workshop. However, emphasis is placed on the use of stubble height data to monitor conditions and adjust management to reduce risk of further degradation and minimize uncertainty. This approach to managing uncertainty was expressed by FS staff, facilitators, and ranchers in the workshop.

The final interpretations and management decisions presented in the plan are similar to claims made by FS staff in workshop discussions, which may suggest that stakeholders had little influence on what was presented in the final plan; however, we suggest an alternative interpretation, which is that FS staff, particularly FS Leadership, actively engaged diverse stakeholders in dialogue before, during, and after the workshop, and so claims made by FS staff in the workshop already reflected their consideration of a broad range of stakeholder perspectives.

As evidence of this, the plan explicitly cites various stakeholder contributions, including references to workshop discussions and prior meetings with ranchers. Specifically, ranchers are recognized for their valuable input into how to "logically and practically" change pasture fencing and livestock rotations to meet resource objectives and accommodate endangered species. In workshop discussions, the District Ranger explained that grazing was only allowed in these sensitive riparian areas because of the ranchers' active participation throughout the planning process, which established the trust and communication needed to implement adaptive management in a responsive manner. In workshop discussions and also follow-up conversations with the lead author, FS staff and ranchers described their work together as a mix of periodic informal conversations and formal planning meetings, in which everyone felt they had a chance to express their concerns and listen to each other. The plan also explicitly cites the facilitators' technical expertise although, notably, in reference to upland site conditions rather than riparian areas, which may reflect tensions over expert status between facilitators and the Riparian Coordinator. Finally, the work of the interdisciplinary FS team is cited throughout with references specifying contributions from various specialists. Thus, we found that FS staff led a broadly collaborative planning process evidenced by the juxtaposition of diverse perspectives in the plan, a final decision reflecting integration of those differences, and explicit acknowledgment of the contributions of diverse stakeholders.

\section{DISCUSSION}

When controversial issues challenge stakeholders' core values and sense of identity, stakeholder groups tend to become polarized and develop competing discourses to strategically promote their own positions (Lewicki et al. 2003, Gee 2005). Individuals in conversation negotiate differences according to their personal views and social context, but such conversations are also historically and socially grounded in larger discourses (Gee 2005, Fairclough 2008). As we analyzed participant claims in the workshop and management plan, we found participants used phrases, stories, and technical references from competing discourses that have historically framed conflicts over riparian grazing on public lands. For example, when one Resource Specialist made the claim that recovery could be maximized and risk of degradation minimized with "maximum return of vegetative matter and vigor," she implicitly referenced an environmentalist discourse, which advocates that livestock should be excluded from riparian areas so that recovery can be maximized for biodiversity and ecological function (e.g., Fleischner 1994). When facilitators cited technical references and court cases, they referenced an agricultural science discourse, which advocates that conservative grazing should continue in riparian areas and that it can be adaptively managed to protect biodiversity and ecological function (e.g., Elmore and Beschta 1987, Wyman et al. 2008). According to critical discourse theory, productive stakeholder engagement requires that individuals in conversation are open to exploring differences and negotiating new meanings with each other, but also that individuals are willing to deconstruct larger polarized discourses that have historically framed controversial issues (Gee 2005, Fairclough 2008). "Transforming conflict into collaboration," as the workshop brochure announced, requires that participants shift from taking sides and advocating for a single discourse to blending and hybridizing discourses through dialogue (Innes and Booher 1999, Putnam and Wondolleck 2003).

Critical discourse theory emphasizes that any negotiation of difference, whether in conversation or written documents, is inherently a negotiation of power, where conclusions and decisions reflect the views of those who have power (Gee 2005, Fairclough 2008). Similarly, recognition of expert knowledge is considered an exercise of power, where expert status grants individuals the power to recognize other experts, resolve differences, and recommend solutions (Fischer 2009, Healy 2009). In this study, we focused on the power of 
facilitators as experts and discussion leaders who resolved differences and established consensus in the workshop, and the power of FS staff who elicited expert knowledge from others and finalized decisions in the plan.

Overall, we found facilitators effectively brought together diverse stakeholders to discuss key differences in riparian management, which is an important and difficult first step in transforming polarized stakeholder relations (Lewicki et al. 2003). However, we found they exercised their power as experts and discussion leaders to subtly favor one particular discourse in the historic conflict over riparian management, namely, an agricultural science discourse, which favors grazing. As they guided discussions, they accentuated differences with Resource Specialists, emphasized commonalities with ranchers, and established consensus or resolution based on their expert status. Although workshop organizers explicitly sought to engage Resource Specialists in these workshops, Resource Specialists had low mean repeat attendance compared to other groups (Table 2). Resource Specialists explained to the lead author that the workshops were frustrating because there was limited time to discuss their concerns and they felt people did not want to hear what they had to say. Facilitators, who uncritically take on the role of instructor or expert, run the risk of undermining trust in a collaborative process by presenting one "right" interpretation of instructional materials when participants may have a diversity of other views (Rixon et al. 2007). As facilitators led discussions and referenced larger discourses, we found they subtly reinforced tensions between ranchers and Resource Specialists and contributed to the polarization of competing discourses.

FS staff, particularly the District Ranger, also led stakeholders to talk about key differences, both in the 2009 workshop analyzed here and in meetings and informal conversations that spanned the two-year planning process (2008-2010). Although the District Ranger used his decision making authority to resolve differences in the management plan, the plan still retained important differences intact. Further, management decisions reflected a blending of the competing discourses of riparian management, rather than preference for one particular discourse. FS staff and ranchers described their satisfaction with the two-year planning process and final management decisions, which suggests that this planning effort contributed, at least in part, to transformation of the historic conflict over riparian grazing on Sprucedale and, thus, an increased understanding of this social-ecological system.

\section{CONCLUSION}

When leaders and participants of collaborative processes carefully consider how to manage differences in perspectives and power and more deliberately focus on exploring and respecting differences, collaborative processes are more likely to enhance learning, transform polarized relationships, and build long-term commitments to adaptive management. In this study, we highlighted the power of experts, discussion leaders, and decision makers, who ultimately determine how diverse stakeholder views are incorporated into conclusions and decisions. We caution that the satisfying appearance of a large group of mixed stakeholders can mask a process subtly dominated by one perspective, which can fuel polarization on controversial issues and limit opportunities for learning. The use of expert knowledge can be especially problematic when it is used to promote one particular perspective, as in the "right" interpretation of field conditions.

In the context of adaptive management, expert knowledge is often elicited to clarify ecological and/or social aspects of system dynamics, while less attention is focused on the socially-situated nature of expert knowledge (e.g., Healy 2009), which we interpret as an important linkage between social and ecological systems. In this study, we applied Fairclough's (2008) critical discourse framework to illuminate how the social dynamics of conflict and difference are linked to ecological interpretations of field conditions and management decisions. With this analysis, we emphasize that discourse is powerful; it is used both to understand and influence social-ecological systems.

While the context of this study was a multistakeholder collaborative planning process, we suggest that conflicts over power and knowledge can be found in any social-ecological system. Thus, any adaptive management effort, whether intentionally designed as a collaborative multistakeholder process or not, can benefit from acknowledging the power dynamics of expert knowledge and authority and from considering how diverse perspectives are managed in decision making. Resilience in complex social-ecological systems requires negotiation among diverse "knowers" and "actors," not simply reliance on expert solutions. Thus, we encourage leaders and participants of adaptive management to become more aware of the value of dialogue to challenge problematic power relations and enhance collaborative learning and adaptive decision making.

${ }^{\dagger}$ Fischer (2009) calls for more constructivist research, which refers to a particular theoretical perspective that falls under the umbrella of constructionist epistemology (see Crotty 2006). This study applies a critical constructivist theoretical perspective (see Kincheloe 2005), similar to that described by Fischer.

$¥$ All proper names have been changed to protect confidentiality.

$\S$ Technically, this was described as a transition from a lentic to a lotic type riparian system.

I Stubble height refers to the amount of vegetation remaining after livestock have grazed an area. 
Responses to this article can be read online at: http://www.ecologyandsociety.org/vol17/iss 1/art19/ responses/

\section{Acknowledgments:}

We thank Karen Kainer, Maria Fernandez-Gimenez, Steven Daniels, and the journal's anonymous reviewers, whose comments significantly strengthened this paper. We also thank Jonathan Dain for his valuable insights into conflict and collaboration and George Ruyle for inspiring research on this topic in the context of the Sprucedale Forest. We gratefully acknowledge the generous support and patience of workshop participants and facilitators and the kindness of the Scott and Bath families. J. Arnold was supported with an Alumni Fellowship from the University of Florida School of Natural Resources and the Environment. Publication of this article was funded in part by the University of Florida Open-Access Publishing Fund.

\section{LITERATURE CITED}

Armitage, D., M. Marschke, and R. Plummer. 2008. Adaptive co-management and the paradox of learning. Global Environmental Change-Human and Policy Dimensions 18 (1):86-98.

Arnold, J. S. 2011. Navigating the power dynamics of learning and communication in collaborative resource management: research to inform practice. Dissertation. University of Florida, Gainesville, Florida, USA.

Bakhtin, M. M., and C. Emerson. 1984. Problems of Dostoevsky's poetics. University of Minnesota Press, Minneapolis, Minnesota, USA.

Bush, R. A. B., and J. P. Folger. 2005. The promise of mediation: the transformative approach to conflict. JosseyBass, San Francisco, California, USA.

Connelly, S., and T. Richardson. 2004. Exclusion: the necessary difference between ideal and practical consensus. Journal of Environmental Planning and Management 47 (1):3-17. http://dx.doi.org/10.1080/0964056042000189772

Cooke, B., and U. Kothari. 2001. Participation: the new tyranny. Zed Books, New York, New York, USA.

Crotty, M. 2006. The foundations of social research: meaning and perspective in the research process. Sage, Thousand Oaks, California, USA.

Daniels, S. E., and G. B. Walker. 2001. Working through environmental conflict: the collaborative learning approach. Praeger, Westport, Connecticut, USA.

Elmore, W., and R. L. Beschta. 1987. Riparian areas: perceptions in management. Rangelands 9(6):260-265.
Fairclough, N. 1989. Language and power. Longman, New York, New York, USA.

Fairclough, N. 2008. Analysing discourse: textual analysis for social research. Routledge, New York, New York, USA.

Fischer, F. 2009. Democracy and expertise: reorienting policy inquiry. Oxford University Press, Oxford, UK.

Fisher, R., B. Patton, and W. Ury. 1991. Getting to yes: negotiating agreement without giving in. Penguin Books, New York, New York, USA.

Fleischner, T. L. 1994. Ecological costs of livestock grazing in western North America. Conservation Biology 8 (3):629-644. http://dx.doi.org/10.1046/j.1523-1739.1994.08030629. $\underline{\mathrm{X}}$

Gee, J. P. 2005. An introduction to discourse analysis: theory and method. Routledge, New York, New York, USA.

Habermas, J. 2000. On the pragmatics of communication. MIT Press, Cambridge, Massachusetts, USA.

Healy, S. 2009. Toward an epistemology of public participation. Journal of environmental management 90 (4):1644-1654. http://dx.doi.org/10.1016/j.jenvman.2008.05.020

Heron, J. 2002. The complete facilitator's handbook. Kogan Page, London, UK.

Hogan, C. 2002. Understanding facilitation: theory and principles. Kogan Page, London, UK.

Innes, J. E., and D. E. Booher. 1999. Consensus building and complex adaptive systems: a framework for evaluating collaborative planning. Journal of the American Planning Association 65(4):412-423. http://dx.doi.org/10.1080/019443 $\underline{69908976071}$

Jacobson, C., K. F. D. Hughey, W. J. Allen, S. Rixecker, and R. W. Carter. 2009. Toward more reflexive use of adaptive management. Society and Natural Resources 22(5):484-495. http://dx.doi.org/10.1080/08941920902762321

Kahane, A. 2007. Solving tough problems: an open way of talking, listening, and creating new realities. Berrett-Koehler, San Francisco, California, USA.

Kaner, S. 2006. Facilitator's guide to participatory decisionmaking. Jossey-Bass, San Francisco, California, USA.

Kincheloe, J. L. 2005. Critical constructivism primer. Peter Lang, New York, New York, USA.

Larson, K. L., D. D. White, P. Gober, S. Harlan, and A. Wutich. 2009. Divergent perspectives on water resource sustainability in a public-policy-science context. Environmental Science and Policy 12:1012-1023. http://dx.doi.org/10.1016/j.envsci. $\underline{2009.07 .012}$ 
Leeuwis, C. 2000. Reconceptualizing participation for sustainable rural development: towards a negotiation approach. Development and Change 31(5):931-959. http://dx. doi.org/10.1111/1467-7660.00184

Lewicki, R. J., B. Gray, and M. Elliott. 2003. Making sense of intractable environmental conflicts: frames and cases. Island Press, Washington, D.C., USA.

Lipscomb, M. E., and R. E. O'Connor. 2002. Democracy and communicative rifts: Foucault, fish, and Yucca Mountain. Administrative Theory and Praxis 24(3):393-414.

Liu, J., T. Dietz, S. R. Carpenter, M. Alberti, C. Folke, E. Moran, A. N. Pell, P. Deadman, T. Kratz, J. Lubchenco, E. Ostrom, Z. Ouyang, W. Provencher, C. L. Redman, S. H. Schneider, and W. W. Taylor. 2007. Complexity of coupled human and natural systems. Science 317(5844):1513-1516. http://dx.doi.org/10.1126/science.1144004

Matteson, M. Y., and G. Wuerthner. 2002. Welfare ranching: the subsidized destruction of the American West. Island Press, Washington, D.C., USA.

Muro, M., and P. Jeffrey. 2008. A critical review of the theory and application of social learning in participatory natural resource management processes. Journal of Environmental Planning and Management 51(3):325-344. http://dx.doi.org/1 $\underline{0.1080 / 09640560801977190}$

Ostrom, E. 2008. The challenge of common-pool resources. Environment 50(4):8-20. http://dx.doi.org/10.3200/ENVT.50 .4.8-21

Pahl-Wostl, C., M. Craps, A. Dewulf, E. Mostert, D. Tabara, and T. Taillieu. 2007. Social learning and water resources management. Ecology and Society 12(2):5.http://www.ecolog yandsociety.org/vol12/iss $2 /$ art5/

Putnam, L. L., and J. M. Wondolleck. 2003. Intractability: definitions, dimensions and distinctions. Pages 35-62 in R. J. Lewicki, B. Gray, and M. Elliott, editors. Making sense of intractable environmental conflicts: frames and cases. Island Press, Washington, D.C., USA.

Quigley, T. M. 2005. Evolving views of public land values and management of natural resources. Rangelands 27 (3):37-44. http://dx.doi.org/10.2111/1551-501X(2005)27.3[37: EVOPLV]2.0.CO;2

Reed, M. S. 2008. Stakeholder participation for environmental management: a literature review. Biological Conservation 141 (10):2417-2431. http://dx.doi.org/10.1016/j.biocon.2008.07.014

Rixon, A., T. F. Smith, B. McKenzie, R. Sample, P. Scott, and S. Burn. 2007. Perspectives on the art of facilitation: a Delphi study of natural resource management facilitators. Australasian Journal of Environmental Management 14:179-191.
Stringer, L. C., A. J. Dougill, E. Fraser, K. Hubacek, C. Prell, and M. S. Reed. 2006. Unpacking "participation" in the adaptive management of social-ecological systems: a critical review. Ecology and Society 11(2):719-740 [online] URL: http://www.ecologyandsociety.org/vol11/iss2/art39/

Susskind, L., S. McKearnan, and J. Thomas-Larmer. 1999. The consensus building handbook: a comprehensive guide to reaching agreement. Sage, Thousand Oaks, California, USA.

Winward, A. H. 2000. Monitoring the vegetation resources in riparian areas. U.S. Department of Agriculture General Technical Report RMRS-GTR-47. U.S Department of Agriculture, Ogden, Utah, USA.

Wyman, S., D. Bailey, M. Borman, S. Cote, J. Eisner, W. Elmore, B. Leinard, S. Leonard, S. Reed, S. Swanson, L. Van Riper, T. Westfall, R. Wiley, and A. Winward. 2008. Riparian area management: grazing management processes and strategies for riparian-wetland areas. U.S. Bureau of Land Management Technical Reference 1737-20. U.S. Bureau of Land Management, Denver, Colorando, USA. 